\title{
Morphological Changes in Narcolepsy
}

\author{
Eun Yeon Joo
}

Sleep Disorder Clinic, Department of Neurology, Samsung Medical Center, Sungkyunkwan University School of Medicine, Seoul, Korea

\section{기면증의 뇌형태 변화}

\author{
주 은 연 \\ 성균관대학교 의과대학 삼성서울병원 신경과학교실 수면클리닉
}

Received December 8, 2013

Revised December 9, 2013

Accepted December 9, 2013

Address for correspondence

Eun Yeon Joo, MD, PhD

Department of Neurology,

Samsung Medical Center,

Sungkyunkwan University

School of Medicine, 50

Irwon-dong, Gangnam-gu,

Seoul 135-710, Korea

Tel: +82-2-3410-3597

Fax: +82-2-3410-0052

E-mail: ejoo@skku.edu
Narcolepsy is a chronic neurological disorder with the abnormal regulation of the sleep-wake cycle, resulting in excessive daytime sleepiness, disturbed nocturnal sleep, and manifestations related to rapid eye movement sleep such as cataplexy, sleep paralysis, and hypnagogic hallucination. Over the past decade, numerous neuroimaging studies, have been performed to characterize the pathophysiology and various clinical features of narcolepsy. Here we review structural findings based on brain magnetic resonance imaging in narcolepsy with cataplexy, which include voxel-based morphometry, cortical thickness analyses, and hippocampal volumetry. The current state of research suggests that structural neuroimaging is a useful tool to investigate and understand the anatomical correlates and brain abnormalities of narcolepsy.

J Korean Sleep Res Soc 2013;10:35-38

Key Words: Narcolepsy, MRI, Morphometry, Cortical thickness, Hippocampus.

\section{서 론}

기면증은 심한 주간졸림증, 수면-각성 행동 교란, 탈력발 작(감정 변화에 의해 신체 일부 혹은 전체 근육의 힘이 일시 적으로 떨어짐)과 수면마비, 입면시 환각과 같은 렘수면장애 증상을 동반하는 질환이다. 특히, 탈력발작을 동반하는 기면 증 환자에서 뇌 시상하부의 히포크레틴 함유 신경원 숫자가 줄어드는 특징이 있는데, ${ }^{1}$ 이는 신경펩타이드인 히포크레틴이 기면증의 발생기전에 중요하다는 것을 보여준다. ${ }^{2-4}$ 또한 기면 증 환자들은 수면-각성에 어려움 외에도 인지기능 저하, 감 정조절의 어려움을 호소하는데, 아직은 그러한 증상들에 대한 신경생물학적 원인이 다 밝혀진 것은 아니다. 신경영상(neuroimaging)은 많은 뇌질환의 발생기전, 진단, 치료효과 등을 평가하는 좋은 방법적 도구로 이용되고 있으며, 생체 내 뇌 구 조와 기능을 매우 정확하게 읽을 수 있는 최첨단 기술발전의 산물이라고 할 수 있다. 대표적인 신경영상 기법으로, 뇌 자기 공명영상(MRI), 뇌 스펙트(single-photon emission computed tomography), 뇌 페트(positron emission tomography)가 있다.
기면증과 같은 수면질환 역시 뇌의 구조적 또는 기능적 이상 에 의해 발생하는 뇌 질환으로 볼 수 있으며, 현재까지 많은 신경영상 결과가 발표되었다. 본 종설에서는 기면증 환자의 뇌 구조 이상을 관찰하고 분석하여, 기면증의 발생기전과 증 상을 연구한 대표적인 MRI 연구 결과를 소개하고자 한다.

\section{화소 기반 형태술 (Voxel-Based Morphometry, VBM)}

1996년 Plazzi 등이 특발성 기면증 환자에서 뇌간 연수의 병변을 관찰하여 보고한 이후, 기면증 환자들의 MRI를 시각 적으로 분석한 연구들이 발표되었다..$^{5-7}$ 뇌간 연수는 수면과 각성 전환을 담당하는 많은 신경원이 분포하는 뇌영역으로 기면증의 발생기전을 추리하기에 매력적인 가설이었으나, 후속 연구자들은 연수의 구조적 이상을 발견하지 못했다. ${ }^{6,7}$ 당시 발견한 연수의 이상은 기면증 관련 변화라기보다는 비 특이적 허혈성 소견으로 간주되며, ${ }^{8}$ 현재는 특발성 기면증 진 단을 위해서는 육안 분석에서 뇌의 구조적 이상이 없어야 
한다는 의견이 지배적이다.

2002년 Draganski 등이 육안적으로 분석했을 때 이상이 없 었던 개개인 환자의 MRI를 모아서 화소 기반 형태술(voxelbased morphometry, VBM)이라는 소프트웨어를 이용하여 집단 분석을 통해 처음으로 뇌시상하부의 회색질 농도의 저 하를 밝혀냈다. ${ }^{9} \mathrm{VBM}$ 은 고화질 $\mathrm{MRI}$ 에서 집단 간 뇌 전체 영역의 회색질과 백색질의 차이를 통계적 비교할 수 있는 방 법이다. Draganski의 발표 이후 많은 연구자들이 VBM 결과 를 발표했는데, 한 연구는 탈력발작을 동반한 기면증 환자에 서 전혀 이상소견을 발견하지 못했으나, ${ }^{10}$ 다른 많은 연구들 에서는 기면증 뇌가 정상인 뇌에 비해 여러 뇌영역에서 회색 질 농도(gray matter concentration, GMC) 또는 부피 (gray matter volume, GMV)의 감소를 보고했다. ${ }^{9.11-14}$ 기면증 환자 뇌시상하부에서 관찰된 $\mathrm{GMC}$ 또는 $\mathrm{GMV}$ 감소 소견은 시상 하부의 신경원 감소가 뇌구조 영상에서도 확인됨을 직접적 으로 보여주는 결과이다.,11 또 다른 연구에서는 아래 관자엽 과 이마엽(inferior temporal/frontal), 이마옆앞(prefrontal) 영 역의 GMV 감소가 기면증 환자의 집중력 저하와 같은 인지 기능 저하를 설명할 수 있는 구조적 결함의 증거라고 설명 했다. 12,13,15 최근 발표된 탈력발작을 동반한 29명 기면증 환 자의 VBM 연구를 보면, 정상인 뇌에 비해 여러 뇌영역들, 양 쪽 시상(bilateral thalami), 좌측 곧은 이랑(left gyrus rectus), 양쪽 이마극 이랑(bilateral frontopolar gyri), 양쪽 짧은 섬 이랑(bilateral short insular gyri), 양쪽 위 이마 이랑(bilateral superior frontal gyri), 우측 위 관자 이랑(right superior temporal gyri), 좌측 아래 관자 이랑(left inferior temporal gyri) 에서 $\mathrm{GMC}$ 감소가 관찰되었다. ${ }^{14}$ 또한 작은 부피 교정법(small volume correction)을 통해 양쪽 nucleus accumbens, 시상하 부, 시상의 GMC 감소도 관찰되었다. Nucleus accumbens와 시상하부의 변화는 히포크레틴 감소와 연관된 기면증 환자 의 심한 주간졸림증과 탈력발작 증상을 설명할 수 있는 중요 한 영상 근거라고 할 수 있다. 아울러 이와 같은 여러 뇌영역 의 회색질 농도의 변화는 기면증 환자에서 관찰되는 수면각성 조절장애, 집중력과 기억력 저하가 뇌의 구조적 이상과 관련되어 있다는 관점을 뒷받침한다. 하지만, 이제까지 발표 된 기면증 $\mathrm{VBM}$ 연구들이 다 같은 결과를 낸 것은 아니다. 사용한 분석 방법(statistical parametric mapping 프로그램 version, GMC와 GMV, grand mean scaling, absolute 또는 relative thresholding)과 대상군의 임상적 특징(탈력발작 동 반 유무, 유병기간, 약물치료 여부 등)의 차이가 연구 간 결 과의 차이를 야기했을 것으로 추정한다. 특히 환자의 임상양 상은 보고마다 매우 다양하여 세 연구들에서는 반 수 이상의 환자들이 주간졸림증에 대한 약물을 복용한 상태였으
며, ${ }^{10,12,13}$ 다른 두 연구들에서는 약물 복용력에 대한 언급이 없었다. ${ }^{911}$ 한 연구에서만 이전에 치료를 받은 적이 없는 drug naïve 환자를 대상으로 연구를 진행했다. ${ }^{14}$ 약물치료 여 부가 뇌 구조적 이상에 영향을 미치는지, 그렇다면 어떤뇌 영역에 미치는가에 대한 추가적인 연구가 필요하다. 이제까 지 출간된 여섯 개의 기면증 환자의 VBM 연구를 비교하면 네 연구에서는 GMV 감소를, ${ }^{11-13}$ 다른 두 연구에서는 $\mathrm{GMC}$ 가 감소했음을 보고했다.,14 $\mathrm{VBM}$ 분석에 있어 최근 많이 사 용하는 optimized VBM은 회색질 농도 차이의 상대적 분포 (GMC; no correction for nonlinear normalization)와 회색질 부피 차이의 절대적 분포(GMV; correction for nonlinear normalization)의 집단 간 차이를 통계적으로 정량화할 수 있는 기법이다. ${ }^{16}$ 현재까지 GMV와 GMC 중 어느 것이 뇌구조의 이상소견을 발견하기에 더 적절하고 예민한가에 대해선 아직 의견 일치가 되지는 않았으며, 추가적인 연구가 더 필요하다.

\section{대뇌피질 두께 측정 (Analyses of Cortical Thickness)}

화소 기반 형태술(VBM) 분석법은 집단 간 회색질 분포를 비교하는 데 있어서는 탁월한 장점을 갖고 있으나, 부분 부 피 변화(partial volume effect)로 인해 뇌고랑(sulcus)이 가려 져 세밀한 회색질 형태의 국지화에 제한점을 가질 수 있다. 인간의 대뇌피질 두께는 약 1.5 4.5 mm로 알려져 있으며, 이 는 신경원(neuron), 신경아교세포(neuroglia)와 신경섬유의 밀도와 배열을 반영한다는 점을 바탕으로, ${ }^{17}$ 대뇌피질 두께 측정법이 뇌질환 연구에 각광받고 있다. ${ }^{17,18} \mathrm{MRI}$ 의 $\mathrm{T} 1$ 영상을 기반으로 하는 대뇌피질 두께 측정법은 뇌피질의 작은 변화 도 예민하게 감지한다는 장점이 있어서, $\mathrm{VBM}$ 이나 부피 측 정법보다 우월한 대안법으로 각광받고 있다. ${ }^{19}$ 방법은 3 차원 다각형 그물망의 각 마디에서, 같은 고랑을 중심으로 서로 등 을 마주보는 고랑 벽의 두께를 정량적으로 측정하게 되어, 깊 은 고랑의 두께도 비교적 정확하게 잴 수 있다는 장점을 갖고 있다. ${ }^{20}$ 현재까지 기면증에서 보고된 대뇌피질 연구는 단 하 나이다. ${ }^{21} 28$ 명의 기면증 환자와 33 명의 정상 대조군에서 대 뇌피질을 각각 측정하여 집단 비교를 시행한 결과, 기면증 환 자의 대뇌피질 두께가 정상군에 비해 전반적으로 얇았다. 국 소적 영역 분석을 보면, 기면증 환자에서 눈확이마엽 이랑 (orbitofrontal gyri), 뒤가쪽과 안쪽 이마엽 피질(dorsolateral and medial prefrontal cortexes), 섬(insula), 띠이랑(cingulate gyri), 중간과 아래 관자이랑(middle and inferior temporal gyri), 아래 마루엽(inferior parietal lobule)의 대뇌피질 두께 가 유의하게 얇았다. 기면증 환자군에서 엡워스졸음척도 
(Epworth Sleepiness Scale)가 높을수록, 즉, 졸음 정도가 심할 수록 좌측 모서리위 이랑(left supramarginal gyrus)의 두께가 얇았고, 벡우울증척도(Beck Depression Inventory)가 높을 수록 좌측 해마곁이랑(left parahippocampal gyrus) 두께가 얇아짐이 관찰되었다. 기면증 환자들의 얇은 이마엽, 둘레엽 (limbic lobe), 마루엽의 피질은 기면증 환자들의 집중력, 기 억력, 감정조절의 장애 및 졸음증의 신경해부학적 근거로 설 명된다. ${ }^{21}$ 흥미롭게도 두 연구의 환자군과 검사기간이 다름 에도 불구하고, 기면증의 비정상적으로 얇은 대뇌피질 영역 의 분포와 $\mathrm{VBM}$ 에서 $\mathrm{GMC}$ 가 감소한 뇌영역의 분포가 많이 겹쳐졌다. ${ }^{14}$ 특히 뒤가쪽 이마엽피질, 눈확이마엽과 관자엽 피질은 이전 $\mathrm{VBM}$ 연구에서 $\mathrm{GMC}$ 가 감소한 뇌영역과 일치 한다. ${ }^{14}$ 반면, $\mathrm{VBM}$ 연구에서 $\mathrm{GMC}$ 감소가 관찰되었던 양쪽 nuclei accumbens와 시상, 시상하부 영역은 피질하 구조물이 어서 대뇌피질 두께측정에서는 변화를 볼 수 없다. 이와 같은 $\mathrm{VBM}$ 연구와 대뇌피질 두께 연구 결과의 공통점은 기면증 의 임상증상과 발병기전을 밝히는 데 높은 신뢰성을 주는 결과로 볼 수 있다.

\section{해마 부피 연구 (Hippocampal Volumetry)}

약 $50 \%$ 이상의 기면증 환자들은 주관적인 기억력과 집중 력저하를 호소한다.22 여러 뇌영역이 기억과정에 관여하지만, 그 중 안쪽 관자엽이 큰 역할을 담당한다는 데는 이견이 없다. 이전의 기면증 환자의 신경영상 연구에서, 안쪽 관자엽 영역 과 관련된 이마엽과 둘레엽의 기능적, 구조적 결함이 보고된 바 있으며, $14,23,24$ 이는 기면증에서 안쪽 관자엽 구조와 기억력 및 감정장애 간의 긴밀한 연관성을 뒷받침하는 소견이다. 안 쪽 관자엽 구조 중 해마부피를 직접 수기 측정한 최근 연구를 보면, 정상군에 비해 기면증 환자들의 양쪽 해마부피가 모두 유의하게 감소했음을 알 수 있다(좌측, 환자군 2,907.2 $\mathrm{mm}^{3}$, 정상군 $3,092.3 \mathrm{~mm}^{3}, p=0.005$; 우측, 환자군 $2,990.8 \mathrm{~mm}^{3}$, 정상 군 3,184.3 mm $\left.\mathrm{mm}^{3}, 0.004\right)$. $^{25}$ 통계학적 차이는 성별, 연령, 두개 강내 부피(intracranial volume)를 교정한 후에도 의미가 있었 다. 기면증 환자군에서 양쪽 해마부피는 다중수면잠복기검 사(multiple sleep latency test)의 평균 수면잠복기와 평균 렘 수면잠복기가 짧을수록 더 줄어드는 양상을 보였다. 한편, 기 면증 환자의 객관적인 기억력 검사 결과는 정상군과 차이가 없었고, 해마부피와 유의한 상관성을 보이지 않았다. 이 연구 는 기면증 환자들이 호소하는 기억력 저하가 해마부피의 감 소와 관련이 있으며, 그 부피는 질병의 중증도와 관련이 있 음을 보여준다는 점에서 의의가 있다.

\section{결 론}

$\mathrm{MRI}$ 를 이용한 신경영상분석법은 기면증 뇌의 기전과 증 상에 대한 유용한 정보를 제공하며, 특히 컴퓨터 분석을 이용 한 새로운 방법들은 히포크레틴 결핍과 관련 있는 시상하부, 탈력발작과 인지기능 및 감정조절장애와 연관된 여러 뇌영 역의 구조적 문제를 보여주었다. 보다 정밀한 MRI 영상의 발 전과 분석소프트웨어의 개발은, 아직은 미지의 영역으로 남 아있는 기면증의 병태생리, 치료효과 및 이를 예측하는 데 있 어 중요한 역할을 담당할 것으로 기대한다.

\section{REFERENCES}

1. Thannickal TC, Moore RY, Nienhuis R, et al. Reduced number of hypocretin neurons in human narcolepsy. Neuron 2000;27:469-474.

2. Taheri S, Zeitzer JM, Mignot E. The role of hypocretins (orexins) in sleep regulation and narcolepsy. Annu Rev Neurosci 2002;25:283-313.

3. Sakurai T, Amemiya A, Ishii M, et al. Orexins and orexin receptors: a family of hypothalamic neuropeptides and G protein-coupled receptors that regulate feeding behavior. Cell 1998;92:573-585.

4. Nishino S, Ripley B, Overeem S, Lammers GJ, Mignot E. Hypocretin (orexin) deficiency in human narcolepsy. Lancet 2000;355:39-40.

5. Plazzi G, Montagna P, Provini F, Bizzi A, Cohen M, Lugaresi E. Pontine lesions in idiopathic narcolepsy. Neurology 1996;46:1250-1254.

6. Bassetti C, Aldrich MS, Quint DJ. MRI findings in narcolepsy. Sleep 1997;20:630-631.

7. Frey JL, Heiserman JE. Absence of pontine lesions in narcolepsy. Neurology 1997;48:1097-1099.

8. Desseilles M, Dang-Vu T, Schabus M, Sterpenich V, Maquet P, Schwartz S. Neuroimaging insights into the pathophysiology of sleep disorders. Sleep 2008;31:777-794.

9. Draganski B, Geisler P, Hajak G, et al. Hypothalamic gray matter changes in narcoleptic patients. Nat Med 2002;8:1186-1188.

10. Overeem S, Steens SC, Good CD, et al. Voxel-based morphometry in hypocretin-deficient narcolepsy. Sleep 2003;26:44-46.

11. Buskova J, Vaneckova M, Sonka K, Seidl Z, Nevsimalova S. Reduced hypothalamic gray matter in narcolepsy with cataplexy. Neuro Endocrinol Lett 2006;27:769-772.

12. Kaufmann C, Schuld A, Pollmächer T, Auer DP. Reduced cortical gray matter in narcolepsy: preliminary findings with voxel-based morphometry. Neurology 2002;58:1852-1855.

13. Brenneis C, Brandauer E, Frauscher B, et al. Voxel-based morphometry in narcolepsy. Sleep Med 2005;6:531-536.

14. Joo EY, Tae WS, Kim ST, Hong SB. Gray matter concentration abnormality in brains of narcolepsy patients. Korean J Radiol 2009;10:552-558.

15. Rieger M, Mayer G, Gauggel S. Attention deficits in patients with narcolepsy. Sleep 2003;26:36-43.

16. Good CD, Johnsrude IS, Ashburner J, Henson RN, Friston KJ, Frackowiak RS. A voxel-based morphometric study of ageing in 465 normal adult human brains. Neuroimage 2001;14(1 Pt 1):21-36.

17. Fischl B, Dale AM. Measuring the thickness of the human cerebral cortex from magnetic resonance images. Proc Natl Acad Sci U S A 2000; 97:11050-11055

18. Kabani N, Le Goualher G, MacDonald D, Evans AC. Measurement of cortical thickness using an automated 3-D algorithm: a validation study. Neuroimage 2001;13:375-380.

19. Hutton C, Draganski B, Ashburner J, Weiskopf N. A comparison between voxel-based cortical thickness and voxel-based morphometry in normal aging. Neuroimage 2009;48:371-380.

20. Im K, Lee JM, Lee J, et al. Gender difference analysis of cortical thickness 
in healthy young adults with surface-based methods. Neuroimage 2006; 31:31-38.

21. Joo EY, Jeon S, Lee M, et al. Analysis of cortical thickness in narcolepsy patients with cataplexy. Sleep 2011;34:1357-1364.

22. Schulz H, Wilde-Frenz J, Grabietz-Kurfürst U. Cognitive deficits in patients with daytime sleepiness. Acta Neurol Belg 1997;97:108-112.

23. Joo EY, Hong SB, Tae WS, et al. Cerebral perfusion abnormality in nar- colepsy with cataplexy. Neuroimage 2005;28:410-416.

24. Joo EY, Tae WS, Kim JH, Kim BT, Hong SB. Glucose hypometabolism of hypothalamus and thalamus in narcolepsy. Ann Neurol 2004;56:437440

25. Joo EY, Kim SH, Kim ST, Hong SB. Hippocampal volume and memory in narcoleptics with cataplexy. Sleep Med 2012;13:396-401. 